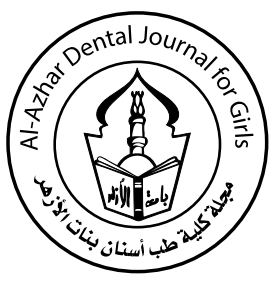

\title{
Prevalence of Enamel Hypoplasia and Enamel Hypocalcification in a Group of Egyptian Children
}

\author{
Karimane Mohamed Aly Osman ${ }^{(1)}$, Eman Sayed El-Masry ${ }^{(2)}$ and Magda Ahmed El-Malt ${ }^{(3)}$
}

Codex : 01/1710

dentaljournal.forgirls@yahoo.com

\begin{abstract}
Purpose. This study was designed to determine the prevalence of developmental enamel defects in a group of Egyptian children and to determine the most common causes of these developmental enamel defects. Subjects and Methods: A total of 1500 children (4-14 years old, 700 boys and 800 girls) were randomly selected from the health insurance public daycare centers. For each child a clinical examination was performed according to the 2013 WHO dental caries criteria and the modified DDE index (FDI, 1982). Children were divided into three groups, according to the type of dentition as follows, group (A) included "692" children and representing the children who had only deciduous dentition, group (B) included " 688 " children and representing the children who had mixed dentition and group (C) included " 120 " children and representing the children who had only permanent dentition. Results: Prevalence of enamel defect were observed in $22.5 \%$ of cases. Conclusion: Prevalence of enamel defect were observed in 337 cases with the most common defect was demarcated opacity which was found in 197 cases $(13.1 \%)$. There was a statistically significant association between presence of enamel defects and previous disease. Previous surgery, previous radiation, previous medication and previous hospitalization. Also, high mean dmf, def and DMF indices, high mean GI. There was no statistically significant association between presence of enamel defects and maternal history during pregnancy, present disease, present intake of medication and familial history of disease
\end{abstract}

\section{INTRODUCTION}

Developmental enamel defects are disturbances during enamel formation and may be manifested as enamel hypoplasia or enamel
Enamel Hypoplasia, Enamel

Hypocalcification, modified DDE index. 
hypocalcification. Hypoplasia is a quantitative defect associated with a reduced or altered amount of enamel. It varies in appearance from pits and grooves to partial or total loss of enamel surface. However hypocalcification is the qualitative defect involving alteration in translucency of enamel. These lesions appear as white, cream, yellow, or brown in color ${ }^{(1)}$. Developmental defects of enamel (DDE) are daily encountered in clinical practice. The knowledge of etiological factors for DDE is essential for clinicians when explaining and discussing the presence of DDE with patients and their parents ${ }^{(2)}$.

The common causes of enamel defects include: inherited (as in amelogenesis imperfecta); excess fluoride intake; and a systemic upset during amelogenesis. However, in some cases, the aetiology is unknown and the condition is termed 'idiopathic enamel hypoplasia (IEH) ${ }^{(3)}$.

Types of hypoplasia include Pits form: tiny areas of enamel loss, which could be single, multiple, shallow or deep, scattered or in rows, Groove (furrow) form: single or multiple, narrow or wide (maximum 2mm) grooves of enamel loss and Area (plane) form: partial or complete absence or enamel over a considerable area of the tooth ${ }^{(4)}$ Types of Hypocalcification (opacity) include Demarcated opacities which are defects involving an alteration in the translucency of the enamel, variable in degree and the defective enamel is of normal thickness with a smooth surface. It has a distinct and clear boundary with the adjacent normal enamel and can be white, cream, yellow or brown in color ,and Diffuse opacities which are defects involving an alteration in the translucency of the enamel, variable in degree and white in color. The defective enamel is of normal thickness and can have a linear, patchy or confluent distribution, but there is no clear boundary with the adjacent normal enamel ${ }^{(5)}$.

Developmental defects in the enamel present important clinical significance since they are responsible for aesthetic problems, increased wear, dental sensitivity, dentofacial anomalies, as well as for a predisposition to dental caries. In the field of public health, developmental defects in the enamel have taken on a high level of importance for being predictors of dental caries. Populations affected by these changes require as a priority preventive intervention and early treatment ${ }^{\left({ }^{(6)}\right.}$.

\section{SUBJECTS AND METHODS}

The study population included 1500 (700 boys and 800 girls) Egyptian children aged 4 to 14 years. Children were randomly selected from a health insurance public daycare center.

\section{Classification of cases}

Children were divided into three groups A,B \& C.

1. Group A: included "692" children and representing the children who had only deciduous dentition.

2. Group B: included " 688 " children and representing the children who had mixed dentition.

3. Group C: included " 120 " children and representing the children who had only permanent dentition.

Every child in this study will be subjected to:

- Extraoral examination: for physical appearance, Skin, extremities, fingers and finger nails, facial symmetry.

- Intraoral examination: the teeth and mouth examined using WHO Basic method of oral health survey ${ }^{(7)}$.The defects were assessed by visual and tactile inspection using directed light without the enamel surface being preliminary dried.

- A dental examination chart was filled to assess the soft and hard tissue condition using caries indices, $\mathrm{dmf}$ index and def index for primary teeth and DMF for permanent teeth and Gingival index GI . 
- Photographs were taken for the child's upper and lower teeth using check retractor and digital Agfa Optima 103 camera.

- A survey questionnaire was designed to collect data from parent of each child.

\section{Statistical analysis}

Qualitative data were presented as frequencies and percentages. Chi-square $\left(x^{2}\right)$ test was used for comparisons between boys and girls as well as the three groups. It was also used to study the association between presence of enamel defects and medical history.Quantitative data were presented as mean and standard deviation values. The significance level was set at $\mathrm{P} \leq 0.05$.

\section{RESULTS}

Enamel defect were observed in 337 cases representing $22.5 \%$. The most common defect was demarcated opacity - white/cream $<1 / 3$ of the crown which was found in 197 cases (13.1\%).

There was no statistically significant difference between prevalence of enamel defects in boys and girls regarding all types of defects except for the following defects:

- Demarcated opacity - yellow/brown at least $2 / 3$ of the crown and

- Diffuse opacities - patchy At least $1 / 3,<2 / 3$ of the crown; boys showed statistically significantly higher prevalence than girls.

There was no statistically significant difference between prevalence of enamel defects in the three groups regarding all types of defects except for the following defects: (Table1)

- Demarcated opacity - white/cream $<1 / 3$ of the crown;

- Demarcated opacity - yellow/brown $<1 / 3$ of the crown;

- Demarcated opacity - yellow/brown, at least $1 / 3,<2 / 3$ of the crown;

- Diffuse opacities - confluent + staining + enamel loss $<1 / 3$ of the crown.

Group III showed the statistically significantly highest prevalence of these defects, followed by Group II then Group I.

Table (1): Comparison between prevalence of enamel defects in the three groups

\begin{tabular}{|c|c|c|c|c|}
\hline Enamel defects & $\begin{array}{c}\text { Group I (692) } \\
N(\%)\end{array}$ & $\begin{array}{c}\text { Group II (688) } \\
N(\%)\end{array}$ & $\begin{array}{c}\text { Group III (120) } \\
N(\%)\end{array}$ & P-value \\
\hline Demarcated opacity - white/cream $<1 / 3$ of the crown & $32(4.6)$ & $130(18.9)$ & $35(29.2)$ & $<0.001 *$ \\
\hline Demarcated opacity - white/cream At least $1 / 3,<2 / 3$ of the crown & $3(0.4)$ & $11(1.6)$ & $1(0.8)$ & 0.092 \\
\hline Demarcated opacity - white/cream At least $2 / 3$ of the crown & $1(0.1)$ & $4(0.6)$ & $1(0.8)$ & 0.322 \\
\hline Demarcated opacity - yellow/brown $<1 / 3$ of the crown & $22(3.2)$ & $44(6.4)$ & $10(8.3)$ & $0.006 *$ \\
\hline Demarcated opacity - yellow/brown At least $1 / 3,<2 / 3$ of the crown & $3(0.4)$ & $11(1.6)$ & $4(3.3)$ & $0.011 *$ \\
\hline Demarcated opacity - yellow/brown At least $2 / 3$ of the crown & $1(0.1)$ & $4(0.6)$ & $0(0)$ & 0.298 \\
\hline Diffuse opacities - lines $<1 / 3$ of the crown & $3(0.4)$ & $7(1)$ & $1(0.8)$ & 0.442 \\
\hline Diffuse opacities - lines At least $1 / 3,<2 / 3$ of the crown & $0(0)$ & $2(0.3)$ & $0(0)$ & 0.307 \\
\hline Diffuse opacities - lines At least $2 / 3$ of the crown & $0(0)$ & $3(0.4)$ & $1(0.8)$ & 0.133 \\
\hline Diffuse opacities - patchy $<1 / 3$ of the crown & $5(0.7)$ & $8(1.2)$ & $2(1.7)$ & 0.532 \\
\hline
\end{tabular}




\begin{tabular}{|c|c|c|c|c|}
\hline Enamel defects & $\begin{array}{l}\text { Group I (692) } \\
\quad N(\%)\end{array}$ & $\begin{array}{l}\text { Group II (688) } \\
\quad N(\%)\end{array}$ & $\begin{array}{l}\text { Group III (120) } \\
\quad N(\%)\end{array}$ & $P$-value \\
\hline Diffuse opacities - patchy At least $1 / 3,<2 / 3$ of the crown & $2(0.3)$ & $8(1.2)$ & $2(1.7)$ & 0.103 \\
\hline Diffuse opacities - patchy At least $2 / 3$ of the crown & $4(0.6)$ & $4(0.6)$ & $1(0.8)$ & 0.942 \\
\hline Diffuse opacities - confluent At least $1 / 3,<2 / 3$ of the crown & $0(0)$ & $3(0.4)$ & $0(0)$ & 0.170 \\
\hline Diffuse opacities - confluent At least $2 / 3$ of the crown & $1(0.1)$ & $1(0.1)$ & $0(0)$ & 0.917 \\
\hline Diffuse opacities - confluent + staining + enamel loss $<1 / 3$ of the crown & $1(0.1)$ & $8(1.2)$ & $2(1.7)$ & $0.039 *$ \\
\hline $\begin{array}{l}\text { Diffuse opacities - confluent }+ \text { staining }+ \text { enamel loss At least } 1 / 3,<2 / 3 \\
\text { of the crown }\end{array}$ & $1(0.1)$ & $8(1.2)$ & $1(0.8)$ & 0.065 \\
\hline Diffuse opacities - confluent + staining + enamel loss At least $2 / 3$ of the crown & $1(0.1)$ & $5(0.7)$ & $0(0)$ & 0.177 \\
\hline Hypoplasia - pits $<1 / 3$ of the crown & $7(1)$ & $10(1.5)$ & $3(2.5)$ & 0.394 \\
\hline Hypoplasia - pits At least $1 / 3,<2 / 3$ of the crown & $1(0.1)$ & $2(0.3)$ & $1(0.8)$ & 0.396 \\
\hline Hypoplasia - missing enamel $<1 / 3$ of the crown & $2(0.3)$ & $7(1)$ & $2(1.7)$ & 0.130 \\
\hline Hypoplasia - missing enamel At least $1 / 3,<2 / 3$ of the crown & $2(0.3)$ & $2(0.3)$ & $1(0.8)$ & 0.612 \\
\hline Hypoplasia - missing enamel At least $2 / 3$ of the crown & $1(0.1)$ & $2(0.3)$ & $0(0)$ & 0.730 \\
\hline Any other defects $<1 / 3$ of the crown & $2(0.3)$ & $0(0)$ & $1(0.8)$ & 0.131 \\
\hline Any other defects At least $1 / 3,<2 / 3$ of the crown & $1(0.1)$ & $0(0)$ & $0(0)$ & 0.558 \\
\hline Diffuse + hypoplasia $<1 / 3$ of the crown & $1(0.1)$ & $0(0)$ & $0(0)$ & 0.558 \\
\hline
\end{tabular}

*: Significant at $P \leq 0.05$

\section{Association between most common diseases and presence of enamel defect}

Regarding Anemia patients, cases with no enamel defects showed statistically significantly higher prevalence than cases with enamel defects.

Regarding Bronchial asthma as well as Epilepsy patients, cases with enamel defects showed statistically significantly higher prevalence than cases with no enamel defect.

While for IDDM and Rheumatic fever patients, there was no statistically significant association between presence of disease and enamel defects
Table (2) Results of chi-square test for the association between common diseases and enamel defects

\begin{tabular}{|c|c|c|c|}
\hline Disease & $\begin{array}{c}\text { No defect } \\
(1163) \\
N(\%)\end{array}$ & $\begin{array}{c}\text { Defect } \\
(337) \\
N(\%)\end{array}$ & P-value \\
\hline Anemia (n, \%) & $41(3.5)$ & $4(1.2)$ & $0.027^{*}$ \\
\hline $\begin{array}{c}\text { Bronchial asthma } \\
(\mathrm{n}, \%)\end{array}$ & $7(0.6)$ & $7(2.1)$ & $0.013^{*}$ \\
\hline Epilepsy (n, \%) & $3(0.3)$ & $5(1.5)$ & $0.007^{*}$ \\
\hline IDDM (n, \%) & $4(0.3)$ & $4(1.2)$ & 0.061 \\
\hline $\begin{array}{c}\text { Rheumatic fever } \\
(\mathrm{n}, \%)\end{array}$ & $8(0.7)$ & $4(1.2)$ & 0.365 \\
\hline
\end{tabular}




\section{DISCUSSION}

Developmental enamel defects (DDE) have been defined as disturbances in hard tissue matrices and their mineralization that arise during odontogenesis. According to their clinical appearances, DDE have been classified as hypocalcification (demarcated opacity, diffuse opacity) or hypoplasia. Enamel hypocalcification is a qualitative defect involving an alteration in the translucency of enamel and may appear white, yellow or brown in color. Enamel hypoplasia is a quantitative defect associated with a reduced enamel thickness ${ }^{(8) .}$

The present study was carried out to determine the prevalence of developmental enamel defects in a group of Egyptian children aged from 4 to 14 years(to cover all dentition types) and to determine the most common causes of these developmental enamel defects. Several clinical indices have been developed to categorize enamel defects and they can be divided into (a) Specific fluorosis indices which identify and categorize only dental fluorosis, and (b) Descriptive indices with no etiological assumption .The modified DDE Index is a descriptive index. It is more practical and comparable index for epidemiological studies and it allows efficient recording of prevalence and severity of enamel defects $^{(9)}$. Finally, the chi-square test was used to statically analyze the results ${ }^{(5,10)}$.

The results of this study showed that the prevalence of enamel defects was $(22.5 \%)$, a finding that was somehow similar to results obtained by a study in Brazilian children who reported $(24.4 \%)^{(6)}$, and a study in Chinese children who reported $(23.9 \%){ }^{(11)}$. Meanwhile the studies who reported higher results are: (99\%) in Australian Aboriginal children ${ }^{(12)}$, $(66 \%)$ in Norwich (England $^{(13)}$, $(58 \%)$ in Australia $^{(14)}$. Observed prevalence differences could be due to specific characteristics of populations with regard to the presence of a particular illness or regional pollutant, as well as methodological aspects, such as index and criteria used. The type of light source used for the exams; if there was tooth brushing, or drying of teeth before the exam; or if only anterior teeth or the whole dentition are examined ${ }^{(15)}$. Populations with lowest enamel hypoplasia as in Japan (2\%) and in Mexico (6\%) could be attributed to the racial differences and diversity of the methodological procedures which were used ${ }^{(16) .}$

The most common defect in this study was demarcated opacity $(13.1 \%)$ this was in agreement with other studies ${ }^{(1,10,17)}$.This was may be caused by transient damage to ameloblasts during the maturation phase that leads to formation of demarcated defects, but the cells are able to recover and resume their normal function ${ }^{(1)}$.

Regarding the gender, it was found that no statistically significant difference between prevalence of enamel defects in boys and girls regarding all types of defects except for the demarcated opacities and diffuse opacities, boys showed statistically significantly higher prevalence than girls, these results were in agreement with the results of other studies in $\operatorname{Iran}^{(18)}$, Brazil $^{(6)}$ and in Mexico $^{(15)}$, they showed no statistically significant relationships with regard to gender, while boys showed higher prevalence than girls in other studies; in China ${ }^{(19)}$, in Malaysia ${ }^{(20)}$,in Iowa ${ }^{(17)}$. Definitive reason for this finding is suggested to be because of greater intra uterine nutritional demands in boys than in girls, since boys weigh more, have more muscle mass, and are developmentally delayed both in the uterus and at birth. Greater nutritional requirements of boys due to more rapid growth make them more susceptible than girls to the formation of enamel defects ${ }^{(1)}$ Meanwhile these results were in disagreement with the results of other studies were girls showed higher prevalence than boys ${ }^{(21,22)}$. This could be related to a cultural factor (the preference for a son within the family), or better nutritional conditions including longer breastfeeding ${ }^{(23)}$, or it could be due to earlier eruption of teeth among girls than boys ${ }^{(24)}$. 
The prevalence among the three groups showed that there was no statistically significant difference between prevalence of enamel defects in the three groups regarding all types of defects except for demarcated and diffuse opacities where Group III showed the statistically significantly highest prevalence of this defect, followed by Group II then Group I. This was assured in other studies ${ }^{(10,17,14)}$ ,this may be due to the period between births to 2 years of age is an active phase of amelogenesis for permanent teeth so any common systemic conditions occurring during this critical period makes the teeth particularly susceptible for formation of DDE (1).

Regarding the association between presence of defects and mean Caries indices, in this study cases of enamel defects showed statistically significantly higher mean dmf, def and DMF than cases without enamel defects. These results were in agreement with the results of other studies ${ }^{(25,26,27)}$, this is seems logical that surface irregularities on the smooth surfaces of the teeth from EHP would promote the colonization of mutans streptococci (MS), other cariogenic bacteria ${ }^{(28)}$, also decreased mechanical properties of defected enamel could be a reason since hypocalcifieded enamel is less mature ${ }^{(29)}$ and have reduced thickness ${ }^{\left({ }^{30)} \text {. }\right.}$

As regards the association between presence of defects and Medical history in this study there was a statistically significant association between presence of defects and previous disease (e.g. Anemia, Bronchial asthma, Epilepsy, IDDM, Rheumatic fever). Disruptions of enamel formation were associated with frequent illness ${ }^{(31)}$. It has been suggested that any health problem prior to 5 years of age can modulate ameloblast activity and therefore impair amelogenesis ${ }^{(32)}$.

For Anemia patients, cases with no enamel defects showed statistically significantly higher prevalence than cases with enamel defects this is assured by certain study who found that there is no significant difference between anemic and normal children ${ }^{(12) .}$ While it's opposite to the results obtained by other studies who found that there is a significant association between dental defects and evidence for anemia ${ }^{(33,34)}$

For Bronchial asthma cases with enamel defects showed statistically significantly higher prevalence than cases with no enamel defects, this was assured by the findings reported by other studies $(32,35,36)$. This can be hypothesized that pediatric asthma patients with dental enamel defects have probably experienced previous episodes of oxygen deprivation and ameloblasts are highly sensitive to oxygen supply ${ }^{(32)}$, also asthma drugs (either inhaled or oral) have been suspected to increase the prevalence of enamel defects ${ }^{(37)}$

For Epilepsy, cases with enamel defects showed statistically significantly higher prevalence than cases with no enamel defects this is confirmed by other studies ${ }^{(38,39)}$ where increased incidence of trauma in epileptic patients during seizures may be a reason of increased incidence of enamel hypoplasia and hypocalcification. Dental tissues being calcified tissues can also be affected by the derangement of mineral metabolism that occurs with antiepileptic drugs, especially during developmental phases ${ }^{(40)}$. Also epilepsy was considered one of the etiologic factors of the defects, this may be caused by antiepileptic drugs as long-term phenytoin therapy is known to cause disturbance in calcium and bone homeostasis ${ }^{(35)}$.

On the other hand the results for IDDM patients, showed no statistically significant association between presence of disease and enamel defects, which may be due to antidiabetic drugs taken by all diabetic children since anti-diabetic medication resulted in normal enamel ultrastructure ${ }^{(41)}$, or the onset of disease begin after enamel formation is completed because enamel once formed is not

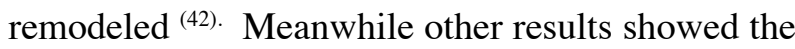
opposite, which reported a decrease in the secretion of enamel matrix forming a thinner enamel layer in diabetes $^{(43,41)}$ 
Regarding Rheumatic fever patients, there was no statistically significant association between presence of disease and enamel defects in all groups which is similar to the results obtained by certain studies ${ }^{(44-46)}$. On the other hand results from other studies ${ }^{(47-49)}$ showed higher prevalence. It is also possible that enamel hypoplasia in cardiac children has resulted from systemic disturbances, such as cardiac failure and surgical complications associated with the cardiac disease during prenatal and neonatal development ${ }^{(45)}$.

As regards association between presence of defects and previous surgery, radiation, medication, and hospitalization. Cases with previous surgery, radiation, medication, and hospitalization showed statistically significantly higher prevalence of enamel defects which is nearly the same obtained by other studies ${ }^{(50,35,42)}$ The reason of this finding is may be due to the fact that dental epithelial cells (ameloblasts) are more sensitive to the drug than dental mesenchymal cells (odontoblasts) the effects depend on the dose of the drug (51).

Concerning cases of previously repaired Clefts, cases in the sample having cleft lip history shows different degrees of enamel hypoplasia and hypocalcification this was assured by certain study $^{(52)}$ that found that there was a significant relationship was found between the cleft side and enamel defects, the highest prevalence on the cleft side suggests that the cleft does influence the occurrence of enamel defects in permanent teeth, this were in agreement with other studies ${ }^{(35,53)}$ and more recently ${ }^{(54)}$ where enamel defects was more common in $\mathrm{CL}(\mathrm{P})$ children in both primary and permanent dentition.

As regards association between presence of enamel defects, maternal history during pregnancy and familial history of disease, there was no statistically significant association between presence of enamel defects, maternal history during pregnancy and familial history of disease, this was disagreed by certain studies ${ }^{(11,55,56)}$, where there was statistically significant association between presence of enamel defects and mothers who had experienced problems during pregnancy while there was no statistically significant association between presence of enamel defects and family history of enamel defects.

\section{CONCLUSIONS}

\section{Based on this study results, the following conclusions can be made:}

1. Prevalence of enamel defect were observed in 337 cases representing $22.5 \%$.

2. There was no statistically significant difference between prevalence of enamel defects in boys and girls regarding all types of defects except for Demarcated and Diffuse opacities; boys showed significantly higher prevalence than girls.

3. There was no statistically significant difference between prevalence of enamel defects in the three groups regarding all types of defects except Demarcated and Diffuse opacities ; Group III showed the statistically significantly highest prevalence of this defect followed by Group II then Group I.

4. There was a statistically significant association between presence of enamel defects and previous disease, mean dmf, def, DMF and GI indices, previous surgery, radiation, medication, and hospitalization.

5. There was no statistically significant association between presence of enamel defects and maternal history during pregnancy, present disease, present intake of medication and familial history of disease. 


\section{REFERENCES}

1. Basha S, Mohamed RN and Swamy HS; Prevalence and Associated Factors to Developmental Defects of Enamel in Primary and Permanent Dentition. 2014; OHDM; 13 (3):588-59.

2. Wong HM; Aetiological Factors for Developmental Defects of Enamel. Austin J. Anat.2014; 1(1): 1003.

3. Fearne J, Anderson $\mathrm{P}$ and Davis GR; 3D X-ray microscopic study of the extent of variations in enamel density in first permanent molars with idiopathic enamel hypomineralisation. Bdj. 2004 ; 196 (10): 634-638.

4. Smith RN, Elcock C, Abdellatif A, Backman B , Russell J.M and Brook AH; .Enamel defects in extracted and exfoliated teeth from patients with Amelogenesis Imperfecta, measured using the extended enamel defects index and image analysis. Arch oral biol.2009; 54: 86 -92.

5. Aminabadi NA, Oskouei SG, Pouralibaba F, Jamali Z and Pakdel F; Enamel Defects of Human Primary Dentition as Virtual Memory of Early Developmental Events. J Dent Res Dent Clin Dental Prospects. 2009; 3(4):110-116.

6. Lunardelli SE and Peres MA; Prevalence and distribution of developmental enamel defects in the primary dentition of pre-school children. Braz. Oral Res.2005; 19(2):144-9.

7. World Health Organization; Oral Health Surveys Basic Methods 5th Edition.2013.

8. Vargas-Ferreira F and Ardenghi TM; Developmental enamel defects and their impact on child oral healthrelated quality of life. Braz Oral Res.2011; 25(6):531-7.

9. Guerra F, Mazur M, Corridore D, Pasqualotto D, Nardi GM and Ottolenghi L; Evaluation of the Esthetic Properties of Developmental Defect of Enamel: A Spectrophotometric Clinical Study. Sci World J. 2015; Article ID 878235.

10. Robles M-J, Ruiz M, Bravo-Perez M, González E and Peñalver MA; Prevalence of enamel defects in primary and permanent teeth in a group of schoolchildren from Granada (Spain) Med Oral Pathol Oral Cir Bucal.2013; 18 (2):e187-193.

11. Li Y, Navia JM and Bian J-Y; Prevalence and distribution of developmental enamel defects in primary dentition of Chinese children 3-5 years old. Community Dentistry and Oral Epidemiology. 2006; 23(2): 72-79.

12. Pascoe L and Seow K; Enamel hypoplasia and dental caries in Australian Aboriginal children: prevalence and correlation between the two diseases. Pediatr Dent. 1994; 16(3):193-199.
13. Khan $\mathrm{H}$; Evaluation of Two Different Indices Using Photographic Method Of Assessment Of Enamel Defects (Opacities) JPMI. 2005; 19(2) :149-156.

14. Seow WK, Ford D, Kazoullis S, Newman B and Holcombe T; Comparison of Enamel Defects in the Primary and Permanent Dentitions of Children from a Low-fluoride District in Australia. Pediatr Dent. 2011; 33:207-12.

15. Casanova-Rosado A.J, Medina-Solís C.E, CasanovaRosado J.F, Vallejos-Sánchez A.A, Martinez-Mier E.A and Loyola-Rodríguez J.P et al., Association between developmental enamel defects in the primary and permanent dentitions. Eur J Pediatr Dent.2011; 12(3): 155-158.

16. Jindal C, Palaskar S and Kler S; The Prevalence of the Developmental Defects of Enamel in a Group of 8-15 Years Old Indian Children with Developmental Disturbances. J Clin Diagn Res.2011; 5(3): 669-674.

17. Slayton RL, Warren JJ, Kanellis MJ, Levy SM and Islam M; Prevalence of enamel hypoplasia and isolated opacities in the primary dentition. Pediatr Dent. 2001; 23:32-36.

18. Daneshkazemi AR and Davari A; Assessment of DMFT and enamel hypoplasia among junior high school children in Iran. The JCDP.2005; 156(4):85-92.

19. King NM; Developmental defects of enamel in Chinese girls and boys in Hong Kong. Adv. Dent Res.1989; $3(2): 120-5$

20. Nik-Hlissein NN, Majid ZA, Mutalib KA, Abdullah F, Abang A 7nd Wan A1N; Prevalence of developmental defects of enamel among 16-year-old children in Malaysia. Annals of Dentistry Univ. Malaya.1999; 6: -11 - 16.

21. Agarwal KN, Narula S, Faridi MMA and Kalra $\mathrm{N}$;Deciduous Dentition and Enamel Defects. Indian J Pediatr. 2003; 40:124-129.

22. Miguel Angel T-L, Rodrigo J, Francisco L, Angel G, Pilar C and Angel Gíl DM; Factors Associated With First Molar Dental Enamel Defects: A Multivariate Epidemiological Approach. : J Dent Child.2003; 70 (3):215-220(6)

23. Tomczyk J, Tomczyk-Gruca $\mathbf{M}$ and Zalewska M; Frequency and chronological distribution of linear enamel hypoplasia (LEH) in the Late Neolithic and Early Bronze Age population from Żerniki Górne (Poland) - preliminary report. Anthropol Rev.2012; 75 (1): 61-73.

24. Hanoon SA; Effect of protein energy malnutrition (PEM) on oral health status of children aged 6 years old in Sammawa city. Orth, Ped, and Prev Dent.2012; 24(2): 150-155. 
25. Farsi N; Developmental enamel defects and their association with dental caries in preschoolers in Jeddah, Saudi Arabia. Oral Health Prev Dent.2010; 8(1):85-92.

26. Fotedar S, Sogi GM and Sharma KR; Enamel hypoplasia and its correlation with dental caries in 12 and 15 years old school children in Shimla, India. J Ind Ass Public Health Dent. 2014; 12 (1): 18-22.

27. Vargas-Ferreira F, Salas MMS, Nascimento GG, Tarquinio SBC, Faggion Jr CM and Peres MA et al., Association between developmental defects of enamel and dental caries: A systematic review and meta-analysis. J. Dent.2015; 43(6): 619-628.

28. Caufield PW, Li Y and Bromage TG; Hypoplasiaassociated Severe Early Childhood Caries - A Proposed Definition. J Dent Res. 2012; 91(6): 544-550.

29. Fagrell TG, Salmon P, Melin L and Norén JG; Onset of Molar Incisor Hypomineralization (MIH). swed dent j.2013; 37: 61-70.

30. Basha S, Roshan Noor Mohamed RN and Swamy HS; Association between enamel hypoplasia and dental caries in primary second molars and permanent first molars: A 3-year follow-up study. Annals of Tropical Medicine and Public Health.2016; 9 (1): 4-11

31. May MRL, Goodman AH and Meindl RS; Response of bone and enamel formation to nutritional supplementation and morbidity among malnourished Guatemalan children. Am J Phys Anthropol. 2005; 92(1): 37-51

32. Guergolette RP, Dezan CC, Frossard WTG, Ferreira FBA, Neto AC and Fernandes KBP; Prevalence of developmental defects of enamel in children and adolescents with Asthma. J Bras. Pneumol.2009 ; 35(4):295-300.

33. Pindborg JJ; Aetiology of developmental enamel defects not related to fluorosis. Int Dent J.1982; 32(2):123-134.

34. Cook DC and Buikstra JE; Health and Differential Survival in Prehistoric Populations: Prenatal Dental Defects. Am J Phys Anthropol.1997; 51: 649-664.

35. Shubha $\mathrm{AB}$ and Hegde $\mathrm{S}$; Molar-Incisor Hypomineralization: Review of its Prevalence, Etiology, Clinical Appearance and Management. Int J Oral \& Maxillofac Patho. 2013;4(1):26-33.

36. Nadja-Marina $\mathrm{K}$ and Adrian L; Molar-incisor hypomineralization. Revue mensuelle suisse d'odontostomatologie.2004; 114(3): 243-253

37. Wogelius P, Haubek D, Nechifor A, Nørgaard M, Tvedebrink T and Poulsen S; Association between use of asthma drugs and prevalence of demarcated opacities in permanent first molars in 6-to-8-year-old Danish children. Community Dent Oral Epidemiol.2010; 38(2):145-51.

38. Verma L, Sharma RK and Singh R; A rare case report of the clinical management of Enamel hypoplasia of epigenetic origin. J Res Med Den Sci.2014; 2(2): 67-70.

39. Cohen HJ and Diner H; The Significance Of Developmental Dental Enamel Defects In Neurological Diagnosis. Pediatrics.1970; 46 (5): 737 -747.

40. Jindal G, Pandey RK and Kumar D; Generalized stunting of roots in an epileptic child: is long-term phenytoin therapy the cause? BMJ Case Reports $10.2012 ; 1136 / \mathrm{bcr}$ 6042 .

41. Atar M, Atar-Zwillenberg DR, Verry P and Spornitz UM; Defective enamel ultrastructure in diabetic rodents. Int. J. Pediatr. Dent.2004 ; 14(4):301-307.

42. Garg N, Jain AK, Saha S and Singh J; Essentiality of Early Diagnosis of Molar Incisor Hypomineralization in Children and Review of its Clinical Presentation, Etiology and Management. Int J Clin Pediatr Dent.2012; 5(3):190-196.

43. Silva-Sousa YTC, Peres LC and Foss MC; Are There Structural Alterations in the Enamel Organ of Offspring of Rats with Alloxan-Induced Diabetes Mellitus? Braz Dent J.2003; 14(3): 162-167.

44. Franco E, Saunders CP, Roberts GJ and Suwanprasit A; Dental disease, caries related microflora and salivary Ig A of children with severe congenital cardiac disease: an epidemiological and oral microbial survey. Pediatr Dent, American Academy of Pediatric Dentistry.1996; 18 (3): 228-235.

45. Zafar S; A Comparative Study of the Oral Health Status of Cardiac and Non-Cardiac Paediatric Patients at Tygerberg Hospital. A minithesis submitted in partial fulfillment of the requirements for the degree of Magister Scientiae in Dental Sciences in the Department of Paediatric Dentistry, Faculty of Dentistry, University of the Western Cape.2008.

46. Zafar S, Yasin-Harnekar S, Siddiqi A and Naz F; Oral Health Status Of Paediatric Cardiac Patients: A CaseControl Study. International dentistry sa.2008; 10 (6): 28-38.

47. Radford DJ; Congenital Heart Disease, in Textbook of Paediatric Practice, YH Thong ed. Sydney.1989; 567-578.

48. Hallett KB, Radford DJ and Seow K; Oral Health of Children With Congenital Cardiac Diseases: A Controlled Study. Pediatr dent.1992; 14 (4): 224-230. 
49. Scully C and Cawson RA; Medical problems in dentistry, 5th Edition Bristol.2005; 4: 53-63.

50. Jälevik B, Norén JG ,Klingberg G and Barregård L; Etiologic factors influencing the prevalence of demarcated opacities in permanent first molars in a group of Swedish children. Eur Jour Oral Sci.2001; 109 (4): 230-4.

51. Bronckers ALJJ, Lyaruu DM, Theodoras J. M. Bervoets TJM and Wöltgens JHM; The effect of colchicine on protein secretion by differentiating odontoblasts and ameloblasts in the hamster tooth in vitro as shown by radio-autography with $3 \mathrm{H}$-proline. Cell and Tissue Research.1988; 252 (3):631-638.

52. Ruiz LA, Maya RR, D’Alpino PH, Atta MT and Svizero NR; Prevalence of Enamel Defects in Permanent Teeth of
Patients with Complete Cleft Lip and Palate. Cleft Palate Craniofac J. 2012; 50(4):394-9.

53. Hall RK; The Prevalence of Developmental Defects of Tooth Enamel (DDE) in a Pediatric Hospital Department of Dentistry Population (Part I) Int J Cli Dent Sci.2010; 1(1).

54. Sundell AL, Nilssona A-k, Ullbrob C, Twetmanc S and Marcussond A; Caries prevalence and enamel defects in 5- and 10-year-old children with cleft lip and/or palate: A case-control study. BMC Oral Health. 2015; 15:85.x

55. Funakoshi DY, Kushida Y and Hieda T; Dental observations of low birth weight infants. Pediatr dent.1981; 3(1):21-25.

56. Needleman HL, Allred E, Bellinger D, Leviton A, Rabinowitz $\mathrm{M}$ and Iverson K; Antecedents and correlates of hypoplastic enamel defects of primary incisors. Pediatr Dent.1992; 14(3):158-166. 